\title{
FRANCISCO CAMPOS E A REFORMA UNIVERSITÁRIA DE 1931: UM RESGATE SOBRE OS SEUS ECOS NO PRINCÍPIO DA AUTONOMIA UNIVERSITÁRIA
}

Mariana Barbosa Cirne ${ }^{1}$

\begin{abstract}
Resumo: Este artigo pretende pesquisar o princípio da autonomia universitária da Reforma Universitária de 1931 que nos dias de hoje tem reflexos nas definições sobre o artigo 207 da Constituição de 1988. A pesquisa se valerá de documentos normativos históricos e de pesquisas doutrinárias sobre Francisco Campos e o seu papel nas definições sobre a educação universitária. Serão analisadas as referências nas decisões judiciais do Supremo Tribunal Federal sobre Francisco Campos e a Reforma Universitária de 1931. Em seguida, será apresentado um pouco do contexto político do Governo Getúlio Vargas e o protagonismo de Francisco Campo. Ao se aproximar da ideologia do Ministro na seara de educação, o que se materializou em suas reformas no setor, almeja-se recuperar traços daquele período que persistem nos discursos de hoje. Por meio desse percurso, busca-se demonstrar a permanência de um pensamento autoritário e centralizador que continua presente na construção de sentidos sobre a autonomia universitária.
\end{abstract}

Palavras-chave: Francisco Campos; Supremo Tribunal Federal; Autonomia; Universidade; Constituição.

\section{FRANCISCO CAMPOS AND THE BRAZILIAN UNIVERSITY REFORM OF 1931: A RESCUE ON YOUR ECOS IN THE PRINCIPLE OF UNIVERSITY AUTONOMY}

Abstract: This article aims to study the principle of university autonomy of the Brazlian University Reform of 1931 which today is reflected in the definitions of Article 207 of the Brazilian Constitution of 1988. The research will make use of historical and normative documents of doctrinal research on Francisco Campos and his role in definitions about university education. The references in the judicial decisions of the Brazilian Federal Supreme Court over Francisco Campos and the University Reform of 1931 will be analyzed. Next, it will be presented a little of the political context of the Getúlio Vargas Government and the protagonism of Francisco Campo. In approaching the ideology of the Minister in the field of education, which materialized in his reforms in the sector, it is hoped to recover traces of that period that persist in the discourses of today. I it is tried to demonstrate the permanence of an authoritarian and centralizing thought that continues present in the construction of meanings on university autonomy.

Keywords: Francisco Campos; Brazilian Federal Court of Justice; Autonomy; University; Constitution.

\footnotetext{
${ }^{1}$ Doutoranda e Mestre em Direito, Estado e Constituição (UnB), especialista em Direito Público (UnP) e em Processo Civil (IDP), e bacharela em Direito (UFPE). Procuradora Federal (AGU) e Professora de Direito Ambiental e de Difusos e Coletivos (UNICEUB). E-mail: marianabcirne@gmail.com
} 


\section{INTRODUÇÃO}

No julgamento da Ação Direta de Inconstitucionalidade $n^{0}$ 51, sobre o artigo 207 da Constituição de 1988, o plenário do Supremo Tribunal Federal realizou uma ampla reflexão sobre o princípio da autonomia universitária e consagrou no papel de "pai das universidades”, Francisco Campos.

A autonomia universitária, objeto da discussão e hoje acolhida no âmbito constitucional, seria a mesma pensada na Reforma Universitária de 1931. Ante essa remissão atual, em julgamento do Supremo Tribunal Federal, o presente trabalho almeja pesquisar o papel de Francisco Campos, Ministro da Educação e Saúde Pública do Governo Getúlio Vargas, na reformulação das estruturas universitárias e na definição das propostas de ensino.

A chamada Reforma Universitária de 1931, que encontra ecos até os dias de hoje, parece merecer maior pesquisa sobre as suas particularidades e características, ante o momento centralizador no Poder Executivo que vivia o Brasil. Por essas razões, este trabalho pretende responder a essas perguntas: quem é o garantidor da ordem institucional das universidades, cuja reforma tem ecos até os dias da Constituição de 1988? Quem é Francisco Campos? Como se deu essa primeira reforma universitária de 1931, referida até os dias de hoje? Que lições podem ser encontradas desse regate para se repensar o princípio da autonomia universitária?

O cerne da pesquisa será, então, a definição do princípio da autonomia universitária, cunhado naquele período, mas que nos dias de hoje tem reflexos nas definições sobre o artigo 207 da Constituição de 1988. A pesquisa se valerá de documentos normativos históricos (decretos, portarias e exposições de motivos) e de pesquisas doutrinárias sobre Francisco Campos e o seu papel nas definições sobre a educação universitária. Em um primeiro momento, serão analisadas as referências presentes nas decisões judiciais do Supremo Tribunal Federal sobre Francisco Campos e a Reforma Universitária de 1931. Em seguida, será apresentado um pouco do contexto político do Governo Getúlio Vargas e o protagonismo de Francisco Campo. Ao se aproximar da ideologia do Ministro na seara de educação, o que se materializou em suas reformas no setor, almeja-se recuperar traços daquele período que persistem nos discursos de hoje. Por meio desse percurso, busca-se demonstrar a permanência de um pensamento autoritário e centralizador que continua presente na construção de sentidos sobre a autonomia universitária, com reflexos no ensino. 


\section{O STF E FRANCISCO CAMPOS}

Conforme anunciado, nos julgamentos do STF sobre a autonomia universitária sobressaiu uma figura importante para a história das universidades: Francisco Campos.

Por essas razões, passa-se a explicar como esses elementos tornaram-se visíveis no primeiro julgado sobre o artigo 207 da constituição, realizado em 1989, pelo Supremo Tribunal Federal. No julgamento da ação direta de inconstitucionalidade - ADI n ${ }^{0}$ 51-9/RJ, proposta pelo Procurador-Geral da República contra o Conselho Universitário da Universidade do Rio de Janeiro ${ }^{2}$ o tema da "Reforma Universitária de

1931” apareceu pela primeira vez. No bojo da ação, a discussão era sobre a nomeação e posse de Reitores e Vice-Reitores pelo Chefe do Poder Executivo, assunto que gera controvérsias até os dias atuais ${ }^{3}$.

No intuito de testar os novos limites da autonomia universitária, a partir de 1988 inserto na seara constitucional, o Conselho Universitário da Universidade Federal do Rio de Janeiro editou a resolução $\mathrm{n}^{\circ}$ 2, de 1988. O intento de tal medida da UFRJ era garantir a eleição e a posse do Reitor e do Vice-Reitor sem a participação do Poder Executivo Federal ${ }^{4}$. Este processo de escolha, nos termos da resolução, caberia apenas à comunidade universitária (docentes, servidores universitários e estudantes) inserindo-se dentro de sua autonomia.

Para declarar a resolução nº 2/88- Conselho Universitário da UFRJ inconstitucional, o Procurador-Geral da República formulou petição inicial pautado nas ofensas à competência legislativa exclusiva da União (artigo 22, XXIV, da CF) e na violação à autonomia universitária (artigo 207 da CF). Observe-se, então, que a autonomia universitária do artigo 207 foi analisada

\footnotetext{
2 Interessante saber que a primeira universidade federal brasileira é exatamente a UFRJ, criada pelo Chefe do Governo Provisório da República dos Estados Unidos do Brasil, pela edição do decreto $\mathrm{n}^{\circ}$ 19.852, de 11 de 1931 (BRASIL, 1931b). Isso parece importante, já que neste tópico pretende-se estudar a reforma universitária de 1931.

${ }^{3}$ Para textos sobre a eleição do reitor e vice-reitor, cf. CUNHA, 2003, p. 151-153. No contexto do Supremo Tribunal Federal, uma demonstração da atualidade do tema pode ser encontrada no comentário do Ministro Sepúlveda Pertence: "É expressivo, aliás, que o tema das eleições das direções universitárias pela comunidade universitária esteve, obviamente, na ordem do dia, há vários anos, nas discussões préconstituintes” (SUPREMO TRIBUNAL FEDERAL, ADI nº 51-9/RJ, p. 34).

${ }^{4}$ Os principais dispositivos da resolução número 2, do Conselho Universitário da Universidade do Rio de Janeiro, dizem o seguinte: “Art. $1^{\circ}$ - O Reitor e o Vice-Reitor da UFRJ serão escolhidos em processo de eleição direta pelos docentes, servidores técnico-administrativos e estudantes, § único - O processo eleitoral iniciar-se-á e encerrar-se-á no âmbito único da UFRJ. Art. $5^{\circ}$ - Os candidatos a Reitor e a ViceReitor vencedores da eleição serão empossados pelo Conselho Universitário” (SUPREMO TRIBUNAL FEDERAL, ADI nº 51-9/RJ).
} 
pela primeira vez pelo Supremo para limitar a atuação das universidades. Em outras palavras, a autonomia foi utilizada como fundamento para restringir a decisão interna da universidade, no caso da UFRJ.

Na primeira oportunidade em que o STF se deparou com o princípio recéminserido na esfera constitucional, o que sobressaiu desse julgamento foi a sua elevação à esfera constitucional. Nas palavras do relator da ADI n 51-9/RJ, Ministro Paulo Brossard, “[...] a norma constitucional, ao assegurar a autonomia universitária, manteve o ‘status quo’ anterior, dando-lhe, porém, a categoria da regra constitucional” (SUPREMO TRIBUNAL FEDERAL, ADI no 51-9/RJ, p. 9). No voto seguinte, o

Ministro Celso de Mello, logo após citar o texto do artigo 207 da constituição de 1988, asseverou:

Operou-se, na realidade, a constitucionalização de um princípio já anteriormente consagrado na legislação ordinária de ensino, que se erigira ao tempo da Reforma Francisco Campos (Decreto n ${ }^{\circ}$ 19.851, de 11 de abril de 1931, artigo $9^{\circ}$ ) - como expressiva garantia de ordem institucional das Universidades (v. FÁBIO PRADO, "A autonomia das universidades estaduais e a competência para baixar seu estatuto e regimento”, in Vox Legis, vol. 147/65, 1981; ANNA CÂNDIDA DA CUNHA FERRAZ, "O regime especial das autarquias educacionais”, in Revista da Procuradoria-Geral do Estado de São Paulo, vol. 17/203204, 1980).

Não há, porém, uma nova autonomia universitária. O que existe, isso sim, é uma nova realidade no panorama do direito constitucional positivo brasileiro. Se, antes, a autonomia das universidades configurava instituto radicado na lei ordinária - e, portanto, supressível por mera ação legislativa ulterior -, registra-se, agora, pelo maior grau de positividade jurídica que a ele se atribuiu, a elevação desse princípio ao plano do ordenamento constitucional. Mas a palavra autonomia continua tendo o mesmo sentido e significado, quer escrita em lei ordinária, quer escrita no texto fundamental (SUPREMO TRIBUNAL FEDERAL, ADI n 51-9/RJ, p. 22-23, grifos do autor).

A autonomia universitária permanecia a mesma de 1931 e a sua elevação ao patamar constitucional representava apenas maior dificuldade de supressão. Seria esse um pensamento isolado? Não. O mesmo raciocínio foi acompanhado por outros ministros do Supremo Tribunal Federal e se repetiu até mesmo nas razões da Consultoria-Geral da União.

No julgamento da MC na ADI nº 1.599-1/UF, sobre o SIPEC (Sistema de Pessoal Civil da Administração Federal) ${ }^{5}$, o Ministro Maurício Corrêa, na qualidade de relator, decidiu adotar

5 Para entender no que consiste o SIPEC, e quais foram os debates deste julgamento, recomenda-se a leitura do tópico correspondente no anexo I. No entanto, para o contexto de hoje, essencial observar o disposto no artigo $9^{\circ}$, decreto $\mathrm{n}^{\circ}$ 7.232, de 19 de julho de 2010 (BRASIL, 2010a). 
as razões da consultora da união, Mirtô Fraga, para abordar o princípio da autonomia universitária. Para tanto, colheu do parecer da consultora o seguinte trecho: “24. Já desde 1931, com o Decreto $\mathrm{n}^{\circ} 19.851$, era reconhecida a autonomia administrativa, didática e disciplinar das universidades” (SUPREMO TRIBUNAL FEDERAL, MC na ADI nº 1.599-1/UF, p. 18).

De tais passagens, dois pontos - espera-se - saltam aos olhos.

O primeiro deles é: quem é o garantidor da ordem institucional das universidades, cuja reforma tem ecos até os dias da constituição de 1988? Quem é Francisco Campos? Como se deu essa primeira reforma universitária de 1931, referida até os dias de hoje?

No próximo tópico, a pergunta será objeto de investigação.

\section{FRANCISCO CAMPOS E A REFORMA UNIVERSITÁRIA DE 1931}

Parece, então, que a figura de Francisco Campos como garantidor da ordem universitária esconde sentidos intrigantes a serem desvendados. Francisco Campos - a que se faz referência no julgado - é, de fato, quem assina juntamente com o Presidente Getúlio Vargas o decreto $\mathrm{n}^{\circ}$ 19.851, de 11 de abril de 1931 (o eixo central da conhecida Reforma Universitária de 1931). De outra parte, o mesmo Francisco Campos também aparece na qualidade de Ministro da Educação e Saúde Pública ${ }^{6}$ quatro meses antes, na assinatura de outro decreto presidencial:

\section{DECRETO N. 19.547 - DE 30 DE DEZEMBRO DE 1930 \\ Cassa a autonomia didática à \\ Universidade de Minas Gerais O Chefe do \\ Governo Provisório da República dos Estados \\ Unidos do Brasil: \\ Atendendo a que será proximamente reorganizado o ensino superior,}

DECRETA:

Art. $1^{\circ}$ Fica, a partir da data do presente decreto, cassada a autonomia didática à Universidade de Minas Gerais. Art. $2^{\circ}$ Revogam-se as disposições em contrário.

Rio de Janeiro, 30 de dezembro de $1930,109^{\circ}$ da Independência e $42^{\circ}$ da República.

GETÚLIO VARGAS

Francisco Campos.

O “pai” das universidades é o mesmo que 4 (quatro) meses antes de reformálas cassou a autonomia didática de uma de suas "filhas". Sob a justificativa de que em seguida reorganizaria o ensino superior, o então Ministro da Educação e Saúde Pública assinou uma medida que cassava a autonomia didática da Universidade de Minas Gerais ${ }^{6}$. Alguns meses

6 O desmembramento entre o Ministério da Saúde e o da Educação só ocorreu em 1953 (ROMANELLI, 2010). 
Mariana Barbosa Cirne

depois, Francisco Campos cumpriu sua promessa e trouxe a público a sua Reforma Universitária de 1931. Ora, mas se poucos meses antes, pareceu necessário cassar a autonomia didática de uma universidade, que termos estariam presentes nessa reforma de 1931?

Um retorno a Francisco Campos - uma figura importante para a história do Brasil pode dar pistas interessantes sobre o pensamento da época, que tem ecos até os dias de hoje. Mas, para pesquisar a história de Francisco Campos $^{7}$ faz-se indispensável resgatar certos traços de seu contexto ${ }^{8}$.

Em 1930, época em que Getúlio Vargas alcança o poder, e Francisco Campos se torna o ministro de Educação e Saúde Pública, o Brasil vivia um momento bastante peculiar. Do contexto internacional, o Brasil sofreu influência da quebra da bolsa de $1929^{9}$ e de ideologias autoritárias $^{10}$ surgidas na Europa após a I Guerra Mundial. No âmbito interno, acresceu-se a esses elementos a crise no modelo de exportação agrícola nacional do café, juntamente com a ambição de industrialização nacional, o que

\begin{abstract}
${ }^{6}$ A Universidade de Minas Gerais foi criada em 1927, por iniciativa de Francisco Mendes Pimentel, e agregava inicialmente as Escolas de Direito, Engenharia e Medicina. Cf. ROMANELLI, 2010, p. 134. A criação da universidade de Minas Gerais foi marcada por generosos subsídios do governo estatal e de seus professores que abriram mão de parte de seus rendimentos para a constituição de um fundo de organização da reitoria (MAYORGA; COSTA; CARDOSO, 2010, p. 28). Não se conseguiu verificar impressões contrárias, ou favoráveis, à cassação da autonomia didática da universidade. No sítio da UFMG, a história da universidade é contada sem ao menos fazer menção a essa cassação da autonomia.

Eis um breve relato de sua história: “A criação de uma universidade no Estado já fazia parte do projeto político dos Inconfidentes. A ideia, porém, só veio a concretizar-se em 1927, com a fundação da Universidade de Minas Gerais (UMG), instituição privada, subsidiada pelo Estado, surgida a partir da união das quatro escolas de nível superior então existentes em Belo Horizonte. A UMG permaneceu na esfera estadual até 1949, quando foi federalizada" (UFMG, 2011a). No Entanto, apareceu como possível pista para tal cassação um decreto editado em 25 de janeiro de 1930, pelo Presidente Washington Luís, que concedia ampla autonomia à UMG (UFMG, 2011a). No recorte histórico, comemorativo dos 80 anos da UFMG, há uma linha do tempo, mas no ano de 1930 não há menção ao decreto presidencial n ${ }^{\circ} 19.547$ (UFMG, 2011b).

7 Eis um breve resumo de seu currículo: “[...] graduou-se em Direito em 1914 pela Faculdade Livre de Direito de Belo Horizonte, instituição pela qual conquistou a cátedra de direito público constitucional já em 1917. A partir de 1919, Campos ascendeu rapidamente na carreira política: foi deputado estadual (1919-1921), deputado federal por duas legislaturas (1921-1926), secretário do Interior (1926-1930), ministro da Educação e Saúde Pública (1930-1932), consultor geral da República (1933-1937) e ministro da justiça (interinamente entre 1930 e 1932 e durante quase todo o período do Estado Novo, de 1937 a 1942)" (MOTA, 2010, p. 40).

${ }^{8}$ Como endossado por Miracy e Dias (2006, p. 7), “[...] a produção do conhecimento é sempre contextualizada. Ela tem um tempo e um espaço e se inicia pela crítica não só de seu contexto como dos próprios meios e teorias que utiliza para a produção do conhecimento jurídico. Foi também advertido por Edgar Morin que "o conhecimento das informações ou dados isolados é insuficiente. É preciso situar informações e dados no seu contexto para que tomem sentido" (MORIN, 2002, p. 40). ${ }^{9}$ Maiores detalhes em MOTA, 2010, p. 30-32.

${ }^{10}$ A tese nacionalista em Francisco Campos não se adjetiva, porém, numa ideologia; é, substantivamente, o Estado, o Poder, o Chefe, com tácitas coincidências de conteúdo, que ele não nomeia nem confessa, respeitantes a análogos modelos europeus de reação totalitária, onde manifestamente se inspirou (CAMPOS, 1979, p. 14). Para mais detalhes sobre o tema, ver SEELAENDER; CASTRO, 2010.
\end{abstract}


oportunizou que setores inicialmente contraditórios ${ }^{7}$ se unissem na figura de Getúlio Vargas ${ }^{8}$.

Eis, em breves linhas, um pouco do contexto que deu ensejo ao Governo Provisório, com o seguinte quadro ministerial:

Presidida por Getúlio, a equipe do novo governo foi composta pelos bacharéis Oswaldo Aranha, ministro da Justiça; Lindolfo Collor, ministro do Trabalho, Indústria e Comércio; José Maria Whitaker, ministro da Fazenda; Joaquim Francisco de Assis Brasil, ministro da Agricultura; Afrânio de Melo Franco, ministro do Exterior; José Américo, ministro da Viação; e Francisco Campos, ministro da Educação; e pelos militares General Leite de Castro, ministro da Guerra e Isaías Noronha, ministro da Marinha (MOTA, 2010, p. 35). Dos importantes personagens da história brasileira, merecerá destaque para o objeto dessa investigação o Ministro da Educação e Saúde Pública, Francisco Campos.

Convém, no entanto, fazer um adendo, pois não se pretende aqui desenhar um perfil maniqueísta de Francisco Campos, como se ele fosse a representação de todos os males do período autoritário de 1930. Ao contrário. A pesquisa está ciente da maleabilidade ${ }^{9}$ do jurista mineiro, o que torna ainda mais interessante sua atuação quanto às universidades. Isso ocorre porque, apesar da flexibilidade de Campos, alguns aspectos parecem estar mantidos em seus discursos, ao acreditar - e defender por várias vezes - uma noção de necessária centralização do poder na figura do Executivo (CAMPOS, 2001). E isso pode ser bastante revelador em um momento político de economia de escala em que as universidades precisam ser "transformadas" para servir às novas condições de vida (MEDEIROS, 1974, p. 63).

Segundo Campos (2001, p. 29), a crise do liberalismo forçou a transformação da democracia, “de regime relativista ou liberal, em estado integral ou totalitário”. Foi o contexto de crise que obrigou a democracia a tomar novos contornos políticos. A exigência de conhecimentos técnicos e especializados (CAMPOS, 2001, p. 31), a lentidão das decisões

7 Otaíza de Oliveira Romanelli (2010, p. 49-53) arrola entre os simpáticos ao regime: os militares superiores, uma parcela dos plantadores de café, parte da elite política de oposição que visavam ao poder, os revolucionários e os tenentes. Jarbas Medeiros (1974, p. 66) marca esse período como a conciliação entre o destino agrário e o futuro industrial do Brasil.

8 Para mais informações, recomenda-se: MARQUES, 2011; MEDEIROS, 1974, p. 59-68.

${ }_{9}^{9}$ Para uma interessante desmistificação da figura de Francisco Campos, e a apresentação de sua flexibilidade como jurista do Estado Novo, recomenda-se SEELAENDER; CASTRO, 2010. Para Darcy Ribeiro (1985, p. 697), sua melhor caracterização se daria como um "mineiro matreiro”. Jarbas Medeiros (1974, p. 69), por sua vez, defende que as convicções pessoais de Francisco Campos detinham peso relativamente pequeno em face de um processo histórico determinado. 
parlamentares (CAMPOS, 2001, p. 34), e as constantes tensões políticas (CAMPOS, 2001, p. 36) desaguaram na solução do totalitarismo, para uma tentativa de "racionalizar o irracional” (CAMPOS, 2001, p. 37). Nessa nova conjuntura, o protagonismo do Poder Executivo era vital. Paulo Bonavides, quando prefacia obra sobre os discursos de Francisco Campos, caracteriza-o exatamente pela ideia da centralização do poder. Define-o como uma figura pública com “[...] uma obsessiva sugestão de ordem, segurança e conservação” (CAMPOS, 1979, p. 13). A centralização do poder parece marcante na posição política do Governo Provisório e de Francisco Campos. Por tal característica, a convicção de Campos parecia conjugar educação com a noção de segurança nacional.

A associação entre educação e segurança nacional - sempre retomada em momentos de política autoritária - tem seu fundamento no fato de que a educação é percebida como instrumento eficaz de controle. Difunde-se a crença de que a educação, bem planejada e disseminada, garante a ordem e a disciplina. Mas talvez o raciocínio possa ser mais bem sustentado ao inverso: a necessidade imperativa da ordem e da disciplina é que define o que será e a que servirá a educação. O período do Estado Novo é rico em exemplos dessa natureza (BOMENY, 2010, p. 267).

Quando falava sobre o papel da educação na constituição de 1937, Campos afirmou que “[...] o Estado precisa exercer de modo efetivo o controle de todas as atividades sociais - a economia, a política, a educação” (CAMPOS, 2001, p. 58). Ora, como se pode imaginar que alguém com ideias tão centralizadoras, pautadas pelo controle, poderia ser o "pai” das universidades?

Dentre os principais feitos de Francisco Campos, na área de educação, encontram-se a reestruturação do Ministério da Educação e Saúde Pública, a discussão sobre a tardia formação da universidade e a criação do Conselho Federal de Educação ${ }^{10}$ (MOTA, 2010, p. 41). Essas são algumas das medidas que, em conjunto, formam a conhecida reforma universitária de 1931. Mas, em se tratando de reformas de um governo autoritário, cabe questionar: sob que

10 A chamada reforma Francisco Campos engloba os seguintes decretos presidenciais: 1) Decreto $\mathrm{n}^{0}$ 19.850, de 11 de abril de 1931, que Cria o Conselho Nacional de Educação; 2) Decreto $\mathrm{n}^{\circ}$ 19.851, de 11 de abril de 1931, que dispõe sobre a organização do ensino superior no Brasil e adota o regime universitário; 3) Decreto $n^{0}$ 19.852, de 11 de abril de 1931, que dispõe sobre a organização da Universidade do Rio de Janeiro; 4) Decreto no 19.890, de 18 de abril de 1931, que dispõe sobre a organização do ensino secundário; 5) Decreto $\mathrm{n}^{\circ} 20.158$, de 30 de junho de 1931, que organiza o ensino comercial, regulamenta a profissão de contador e dá outras providências e 6) Decreto $\mathrm{n}^{\circ}$ 21.241, de 14 de abril de 1932, que consolida as disposições sobre a organização do Ensino Secundário. 
perspectivas se dariam tais inovações? E por que se mantêm essas referências até os dias de hoje?

A finalidade da reforma universitária (decreto $n^{\circ}$ 19.851/31) parece transparecer nos seus primeiros artigos:

Art. $1^{\circ} \mathrm{O}$ ensino universitário tem como finalidade: elevar o nivel da cultura geral, estimular a investigação científica em quaisquer domínios dos conhecimentos humanos; habilitar ao exercício de atividades que requerem preparo técnico e científico superior; concorrer, enfim, pela educação do indivíduo e da coletividade, pela harmonia de objetivos entre professores e estudantes e pelo aproveitamento de todas as atividades universitárias, para a grandeza na Nação e para o aperfeiçoamento da Humanidade.

Art. $2^{\circ} \mathrm{A}$ organização das universidades brasileiras atenderá primordialmente, ao critério dos reclamos e necessidades do País e, assim, será orientada pelos fatores nacionais de ordem psíquica, social e econômica e por quaisquer outras circunstâncias que possam interferir na realização dos atos desígnios universitários (BRASIL, 1931a, grifos nossos).

A universidade une-se aqui à ideia de nação ${ }^{11}$. A universidade parece deixar de ser 0 espaço livre, para atender especificamente aos reclamos e necessidades do País. O caráter instrumental ${ }^{12}$ da proposta aparece ainda nos primeiros artigos da reforma.

Outro ponto da reforma de 1931 que aparece como marcante, e perdura até os dias de hoje, é a organização de um sistema nacional ${ }^{13}$. Perceba-se que até a Reforma Francisco Campos, cada sistema estadual ${ }^{14}$ existia por si só, sem qualquer articulação nacional

11 No seu livro Estado Nacional, Francisco Campos explica o papel da nação na "teologia monista do nacionalismo”, como mecanismo hábil a reforçar a unidade política do Estado, em contraposição ao politeísmo político de Sorel. Para entender mais essa justificativa para uma visão centralizadora, ver CAMPOS, 2001, p. 17-18.

12 Para uma leitura da reforma de 1931 como mecanismo ideológico, com objetivo de impedir os trabalhadores e a classe média de se organizarem contra a ordem capitalista, Cf. CUNHA, 1981, p. 282317.

13 Nesse sentido, o decreto $n^{\circ}$ 19.851: “Art. $3^{\circ}$ O regime universitário no Brasil obedecerá aos preceitos gerais instituidos no presente decreto, podendo, entretanto, admitir variantes regionais no que respeita à administração e aos modelos didáticos. [...] Art. $5^{\circ}$ A constituição de uma universidade brasileira deverá atender às seguintes exigências: (...) IV, submeter-se às normas gerais instituidas neste Estatuto”. (BRASIL, 1931a).

${ }^{14}$ Como as diretrizes do ensino até a reforma universitária de 1931 eram formuladas pelos Estados, as novas concepções como a do “Movimento das Escolas Novas” só se tornaram realidade em cada um dos respectivos Estados em épocas distintas e por reformas diferentes. Otaíza de Oliveira Romanelli narra da seguinte forma esse processo: “[...] a contar de 1922, começaram a aparecer as reformas estaduais de ensino, prenúncio das reformas nacionais que surgiriam a partir de 1930. A primeira delas foi empreendida em 1920, por Sampaio Dória, em São Paulo; em 1922/1923, no Ceará, Lourenço Filho empreendeu a segunda. Depois, seguiram- 
(ROMANELLI, 2010, p. 133). Isso tornava particularmente difícil a gestão do ensino superior, pois não havia diretrizes gerais. Por isso, não se pode negar o mérito de Francisco Campos, e de sua reforma, ao conferir uma estrutura orgânica ao ensino secundário, comercial e superior ${ }^{19}$. Ao mesmo tempo em que se identificam pontos positivos ${ }^{15}$ na Reforma Universitária de 1931, o mesmo não pode ser dito sobre a sua proposta de autonomia às instituições superiores. Isso porque, como ressaltado na exposição de motivos do decreto de 1931, a autonomia universitária de 1930 seria de natureza relativa. A justificativa para a sua relatividade se encontrava no seu sentido inaugural no ordenamento brasileiro:

Embora não o consagrando em toda a sua latitude, o projecto, pelas tendências manifestas que revela, se deixa orientar pelo critério da autonomia administrativa e didactica das Universidades. Seria, porém, de todo ponto inconveniente e mesmo contraproducente para o ensino, que, de súbito, por uma integral e repentina ruptura com o presente, se concedesse ás Universidades ampla e plena autonomia didactica e administrativa. Autonomia requer prática, experiência e critérios seguros de orientação. Ora, o regimen universitario ainda se encontra entre nós na sua phase nascente, tendo os primeiros passos e fazendo os seus ensaios de adaptação. Seria de mau conselho que, nesse período inicial e ainda embryonario e rudimentar da organização universitaria, se tentasse, com risco de graves damnos para o ensino, o regimen da autonomia integral.

Este, o motivo pelo qual o projecto preferiu a orientação prudente e segura da autonomia relativa, destinada a exercer uma grande função educativa sobre o espirito universitario, que na sua pratica adquirirá a experiencia e o critério indispensaveis a uma autonomia mais ampla, seja no terreno administrativo, seja no domínio didactico (CAMPOS, 1940, p. 62-63).

se a do Rio Grande do Norte, por José Augusto (1925/1928), as do Distrito Federal (1922/1926) e as de Pernambuco (1928), empreendidas ambas por Carneiro Leão, a do Paraná (1927/1928), por Lysímaco da Costa, a de Minas Gerais (1927/1928), por Francisco Campos; a do Distrito Federal (1928), por Fernando Azevedo; e a da Bahia (1928), por Anísio Teixeira” (2010, p. 130). ${ }^{19}$ Roberto Romano, no entanto, vê a federalização do ensino superior como grande entrave à efetivação da autonomia universitária. Segundo o autor, "sem autonomia, governadores, prefeitos, reitores são apenas um elo da imensa cadeia do favor que rege a vida política nacional. É quase impossível mudar aquela forma de poder, que centraliza todas as políticas públicas nos gabinetes do Executivo federal” (ROMANO, 2008, p. 57).

15 Até mesmo Anísio Teixeira consegue identificar pontos positivos na Reforma Francisco Campos, dentre os quais destaca a possibilidade de uma escola de letras, ciências e educação substituir uma das escolas tradicionais na constituição da universidade (TEIXEIRA, 1989, p. 105-107). No entanto, o próprio autor se decepciona depois com as baixas possibilidades transformadoras desse novo curso. 
Ora, e essa autonomia, incipiente ${ }^{16}$ e relativa pode ser equiparada àquela prevista no artigo 207 da constituição de 1988? Será que essa ausência de experiência ainda se aplica aos dias de hoje?

Note-se que o raciocínio da exposição de motivos se reflete na redação do decreto. Além de uma autonomia relativa, expressamente, no artigo $9^{\circ}$, o decreto ainda prevê outras limitações:

As universidades gozarão de personalidade jurídica e de autonomia administrativa, didática e disciplinar, nos limites estabelecidos pelo presente decreto, sem prejuízo da personalidade jurídica que tenha ou possa ser atribuida pelos estatutos universitários a cada um dos institutos componentes da universidade.

Parágrafo único. Nas universidades oficiais, federais ou estaduais, quaisquer modificações que interessem fundamentalmente a organização administrativa ou didática dos institutos universitários, só poderão ser efetivadas mediante sanção dos respectivos governos, ouvido o Conselho Nacional de Educação (BRASIL, 1931, grifo nosso).

A pretensa autonomia reconhecida no artigo $9^{\circ}$, além de se limitar aos preceitos do decreto $\mathrm{n}^{\circ}$ 19.851, é duramente restringida pela “sanção dos respectivos governos” e pela oitiva do Conselho Nacional de Educação. Cabe então perguntar: alguma margem foi deixada para as universidades?

Para aqueles que ainda possam qualificar o instituto como benevolente às instituições universitárias, não custa lembrar que neste período praticamente não existiam universidades no Brasil $^{17}$. Em face de tal panorama, os limites do decreto podem desvendar outros sentidos, quando se conjuga a interpretação do artigo 9 (já transcrito) com o $7^{\circ}$ :

A organização administrativa e didática de qualquer universidade será instituida em estatutos aprovados pelo ministro da Educação e Saude Pública e que só poderão ser modificadas por proposta do Conselho Universitário ao mesmo Ministro, devendo ser ouvido o Conselho Nacional de Educação.

Mesmo a organização didática, bem como a administrativa, deveria estar prevista nos estatutos universitários a serem aprovados pelo Ministério da Educação e Saúde Pública. O

16 Luiz Antônio Cunha faz um paralelo entre essa autonomia relativa, incipiente, das universidades e a postura do autoritarismo quanto ao povo, incapaz de dirigir os seus caminhos, sem a ajuda das elites. Cf. 1981, p. 298.

17 Os poucos exemplos universitários são os seguintes: "Em 1920 foi criada a Universidade do Rio de Janeiro (Decreto n. 14.343); em 1927, a Universidade de Minas Gerais (Lei Estadual n. 956); e em 1934, a Universidade de São Paulo, esta última pelo governo do Estado (Decreto Estadual n. 6.533)” (RANIEIRI, 2005b, p. 19). 
mesmo regime se aplicaria às alterações e aos institutos singulares ${ }^{18}$. Identifica-se, portanto, quanto poder em verdade estava reunido nas mãos do então Ministro Francisco Campos. A autonomia aqui era menos do que relativa. Revelando o seu caráter centralizador, Nina Ranieri explica que “[...] o decreto, simultaneamente, proclamava e cerceava a autonomia das universidades, reafirmando com este mecanismo controle e centralização” (RANIERI, 1994, p. 80). Maria de Lourdes Fávero (1998, p. 10) chega a essa mesma conclusão.

No caso da autonomia didática, o decreto previu ainda outra ressalva:

Art. 11. Qualquer universidade poderá ampliar a sua atividade didática pela encorporação progressiva de novos institutos de ensino superior de natureza técnica ou cultural, mediante prévia aprovação do Conselho Universitário da respectiva universidade.

$\S 1^{\circ}$ A encorporação, para ser efetivada, dependerá, nas universidades federais, de decreto do Governo Federal e, nas universidades equiparadas, de ato do ministro da Educação e Saude Pública, devendo ser ouvido o Conselho Nacional de Educação.

Modificações didáticas dependem, em suma, de um decreto do Governo Federal, no caso das federais, e nas outras hipóteses, de ato de Ministro da Educação e Saúde Pública. E, cabe questionar, ainda restava alguma autonomia?

Não por acaso, a reforma universitária de 1931 é entendida como uma moldura legal centralizadora do Governo Vargas (SAMPAIO, 2003, p. 145). Apesar disso, continua a ser citada em vários trabalhos - além das referências em decisões judiciais do Supremo Tribunal Federal - como exemplo de reforma universitária que confere às instituições universitárias uma forma de autonomia. Será mesmo?

Note-se que a centralização era tanta que até mesmo a nomeação dos Diretores de cada Faculdade seria decidida pelo Governo ${ }^{19}$. No caso da figura dos ConselhosTécnicos - órgãos

18 Cf. art. 111, do decreto $\mathrm{n}^{0}$ 19.851: “O Governo instituirá, em regulamentação especial, o regime administrativo e didático dos institutos federais localizados nos Estados, enquanto os mesmos não se integrarem em unidade universitária, devendo adotar na mesma regulamentação as normas gerais estabelecidas no presente Estatuto. Parágrafo único. As questões didáticas e administrativas que interessem a esses institutos singulares serão resolvidas pelo ministro da Educação e Saude Pública, ouvido o Conselho Nacional de Educação” (BRASIL, 1931a).

19 Cf. art. 27, do decreto $\mathrm{n}^{0}$ 19.851: "O diretor dos institutos universitários federais - orgão executivo da direção técnica-administrativa - será nomeado pelo Governo, que o escolherá de uma lista tríplice na qual serão incluidos os nomes de três professores catedráticos, em exercício, do mesmo instituto, dois deles eleitos por votação uninominal pela respectiva Congregação e eleito o terceiro pelo Conselho Universitário. $\S 1^{\circ} \mathrm{O}$ Conselho Universitário, recebida a lista da Congregação e acrescida do nome de sua escolha, deverá enviar a proposta de nomeação ao Governo dentro do prazo máximo de trinta dias a contar da data em que se verificou a vaga. $\S 2^{\circ}$ Se, dentro do prazo acima fixado, não for enviada a proposta de que trata 
deliberativos criados pelo Decreto - a escolha caberia, entre uma lista de nomes, ao Ministro de Educação e Saúde Pública ${ }^{20}$. Havia, portanto, dependência administrativo-burocrática de cada Escola (que segundo o decreto, em sua junção formariam uma universidade) ao Governo (ROMANELLI, 2010, p. 136). Apesar de todas essas características, na exposição de motivos do projeto de decreto, Francisco Campos explicou que os órgãos de direção técnica e administrativa seriam o Reitor e o

Conselho Universitário, dependendo a universidade do Ministro da Educação "em raros assuntos financeiros e administrativos” (CAMPOS, 1940, p. 64, grifo nosso). Raros?

No entanto, as previsões normativas do decreto parecem comprovar que a universidade está - em todos os seus mínimos aspectos - submetida ao crivo do Governo ${ }^{21}$.

Apesar de Campos se apropriar de um discurso que prega a ideia de ensino superior que abarcaria as concepções “mais radicaes às mais conservadoras” (CAMPOS, 1940), os termos da instituição da Universidade do Rio de Janeiro ${ }^{22}$ parecem atestar exatamente o

o parágrafo anterior, nomeará o Governo o diretor, escolhendo-o livremente dentre os professores catedráticos do mesmo instituto. $\S 3^{\circ} \mathrm{O}$ diretor terá exercido pelo prazo de três anos e só poderá figurar na lista tríplice seguinte pelo voto de dois terços da Congregação ou do Conselho Universitário” (BRASIL, 1931a).

20 Cf. art. 29, do decreto $n^{\circ}$ 19.851: "O Conselho técnico-administrativo - orgão deliberativo de acordo com o dispositivo regulamentar de cada um dos institutos das universidades federais, será constituido de três ou seis professores catedráticos, em exercício, do respectivo instituto, escolhidos pelo ministro da Educação e Saude Pública e renovados de um terço anualmente. § $1^{\circ}$ Para a constituição, renovação ou preenchimento de vagas do Conselho, a Congregação organizará uma lista de nomes de professores com um número duplo daquele que deva constituir, renovar ou completar o mesmo Conselho, devendo entre eles recair a escolha do ministro da Educação e Saúde Pública. $\S 2^{\circ}$ A eleição será por escrutínio secreto e cada membro da Congregação votará apenas em tantos nomes distintos quantos os necessários à constituição, renovação ou preenchimento de vagas do respectivo Conselho” (BRASIL, 1931).

${ }^{21}$ Note-se que na postura do autoritarismo de Francisco Campos essa concentração do poder na figura do

Presidente da República detém um caráter democrático, diante do seu contato direito com o povo

(CAMPOS, 2001, p. 60). Nos contornos do Estado Novo, a máquina estatal, “[...] toda ela é constituída em torno de uma ideia central, favorável à ação eficaz do governo: o governo gravita em torno de um chefe, que é o Presidente da República” (CAMPOS, 2001, p. 61).

${ }^{22}$ Convém esclarecer que a Universidade do Rio de Janeiro foi criada pelo decreto $\mathrm{n}^{\circ} 14.343$, de 07 de janeiro de 1920, mas com a reforma universitária de 1931, sofreu enorme reformulação pelo decreto $\mathrm{n}^{\circ}$ 19.852, de 11 de Abril de 1931 (RANIERI, 1994). 
contrário. Os motivos para defender nessa investigação que houve a manutenção de uma ideia centralizadora são muitos.

Em primeiro lugar, houve a agregação de várias faculdades ${ }^{23}$, mesmo que em Estados diferentes (Rio de Janeiro e Minas Gerais), em uma única universidade. Não bastasse isso, na definição de cada um dos cursos da Universidade de Rio de Janeiro ${ }^{24}$ - direito, medicina, engenharia ${ }^{30}$, odontologia, belas artes e música - pode-se perceber que as diretrizes foram radicalmente modificadas pela Reforma de 1931.

No curso de direito, por exemplo, Francisco Campos delimitou quais seriam as disciplinas ${ }^{25}$ lecionadas e explicou que seria dispensável o ensino do direito romano. Em suas palavras, ele estaria inserindo na norma algo que já ocorreria na prática, pois o que se ensinava nas faculdades como direito romano "eram noções gerais de direito".

Em suma: “a reforma limitou-se, portanto, a consagrar na lei uma situação de facto” (CAMPOS, 1940, p. 74). No caso de medicina, um dos objetivos era "promover o

aperfeiçoamento progressivo de nossa raça” (CAMPOS, 1940, p. 77), o que deveria ser implementado pela incorporação, da "pesquisa scientifica original” (CAMPOS, 1940, p. 78) no processo didático. Ainda na mesma proposta “[...] foram retiradas do curso medicos cadeiras de physica, de chimica geral e mineral e de chimica orgânica [...]” (CAMPOS, 1940, p. 81), pois segundo Francisco Campos não eram mais necessárias. Na engenharia, foram propostas as aulas de debate e arguição e houve a criação de 4

23 Cf. art. $1^{\text {o }}$, do decreto $\mathrm{n}^{\circ}$ 19.852: "Ficam congregados em unidade universitária, constituindo a Universidade do Rio de Janeiro, os institutos de ensino superior abaixo enumerados, acrescidos da Faculdade de Educação, Ciências e Letras, criada pelo presente decreto: a) Faculdade de Direito; b)

Faculdade de Medicina;

c) Escola Politécnica; d) Escola de Minas; e) Faculdade de Educação, Ciências e Letras; f) Faculdade de Farmácia; g) Faculdade de Odontologia; h) Escola Nacional de Belas Artes e i) Instituto Nacional de Música” (BRASIL, 1931b).

24 Para conferir as ponderações sobre cada um desses cursos universitários: CAMPOS, 1940, p. 73-100. ${ }^{30}$ Uma das reformas mais emblemáticas ocorre no curso de engenharia, com a criação de novas cadeiras, desmembramento de outras e reforço nos conhecimento de Physica, ante a reconhecida deficiência do ensino secundário deste tema. Cf. CAMPOS, 1940, p. 83-95. 25 Ver: art. 27, do decreto $n^{0}$ 19.852: O curso de bacharelado em direito compreenderá o ensino das seguintes matérias: Introdução à Ciência do Direito; Economia Política e Ciência das Finanças; Direito Civil; Direito Penal; Direito Público Constitucional; Direito Público Internacional; Direito Comercial; Direito Judiciário Civil; Direito Judiciário Penal; Direito Administrativo; Medicina Legal (BRASIL, 1931b). 
(quatro) novas cadeiras, sendo a última sobre "photo-topographia”, que poderia ser estudada no “Serviço Geographico Militar” (CAMPOS, 1940, p. 90-91).

O grau de inserção na delimitação didática dos cursos foi tanta que os currículos foram abertamente reformulados, mesmo em área de pretensa ausência de conhecimento de Francisco Campos. Quanto ao curso médico, o então ministro explicou que “[...] uma das cadeiras de clinica cirúrgica foi transformada em clinica urológica, attendendo-se, assim, á exigência evidente do ensino profissional, sem o menor prejuizo para o ensino da cirurgia geral, ministrado em duas cadeiras” (CAMPOS, 1940, p. 81). Até mesmo o número de cadeiras ${ }^{26}$ a ser ministrado em cada disciplina foi alterado pela Reforma Universitária de 1931.

Outro ponto que sobressai nos decretos é a ideia de concorrência dentro da universidade. Esse alvitre aparece em vários pontos da reformulação dos concursos $^{33}$ para docentes e na reformação da Faculdade de Educação, Sciencia e Letras (CAMPOS, 1940, p. 65-73). Segundo Campos, para o crescimento do país, e o desenvolvimento de novas tecnologias, era essencial estimular a competição entre os professores.

Um último tema da reforma universitária de 1931 - mas não menos importante merece ser apresentado: o Conselho Nacional de Educação (CNE). Para quem olhasse rapidamente o projeto, poderia identificar uma proposta para reduzir o caráter administrativo e burocrático das universidades. No entanto, a centralidade do poder ainda se verifica no seu objetivo. A criação do CNE buscava eleger, como seus componentes “[...] um grupo de elite, escolhido dentre o que temos de melhor em matéria de cultura e de educação”, que poderá exercer essas altas e nobres funções de orientação e de conselho” (CAMPOS, 1940, p. 101). Nas palavras de Campos, o CNE contribuirá com a sua “[...] influência e autoridade, para que se mantenham as linhas claras, firmes e definidas, segundo as quaes a presente reforma procura

${ }^{26}$ E note-se que não foram só essas as modificações da reforma. Francisco Campos (1940, p. 82) ainda adverte: "outras disposições, que escapam a esta enumeração synthetica, foram introduzidas no regime administrativo e didactico das Faculdades medicas, sempre com o empenho de melhorar e corrigir”. $\quad{ }^{33}$ A esta pesquisa parece particularmente interessante um dos requisitos do concurso de professor catedrático, previsto no decreto $\mathrm{n}^{\circ}$ 19.851: Art. 51. Para a inscrição ao concurso de professor catedrático o candidato terá que atender a todas as exigências instituídas no regulamento do respectivo instituto universitário, mas, em qualquer caso, deverá: [...] III, apresentar provas de sanidade e idoneidade moral; (BRASIL, 1931a, grifo nosso). 
orientar as atividades didacticas e culturaes dos nossos institutos de ensino" (CAMPOS, 1940, p.

101).

E esse pensamento centralizador na história de Francisco Campos, não se resume ao episódio da reforma universitária de 1931. Com o advento do Estado Novo, a nova ordem foi marcada pela militarização do ensino ${ }^{27}$ (BOMENY, 2010, p. 269). Na conjugação de educação e ordem, os militares defendiam - com a ajuda do então Ministro da Justiça, Francisco Campos - que o ensino não poderia estar sujeito a críticas ou anulações.

Seguindo essa linha de raciocínio, uma política de mobilização nacional foi proposta em 1930, por Francisco Campos ${ }^{28}$ : a Organização Nacional da Juventude ${ }^{29}$ (ONJ). Buscava-se com tal intento uma educação pré-militar para a juventude (na faixa etária dos oito aos dezoito anos) a ser implementada no Estado Novo. A militarização da juventude, ao tempo em que evitaria o individualismo pernicioso do liberalismo, também garantiria o controle dos possíveis excessos da juventude (BOMENY, 2010, p. 269-271).

27 Para uma interessante crítica ao sistema universitário americano, quanto ao seu direcionamento para o mercado e para as demandas militares, ver: GIROUX, 2010, p. 25-38. Quando delimita os aspectos da atual crise universitária, Henry Giroux (2010, p. 27) explica: “O Ensino Superior nos Estados Unidos e em outros países está perdendo cada vez mais o seu caráter público e seu compromisso com a vida pública, uma vez que se alinha com poderes e valores corporativos e militares".

28 É curioso que, apesar de o projeto da Organização Nacional da Juventude tratar de uma organização paramilitar, de cunho essencialmente educativo, apenas o Ministério da Justiça sendo o Ministro de Estado Francisco Campos -, da Guerra, de Negócios Interiores e da Marinha, além do Presidente Getúlio Vargas, participaram da sua elaboração, excluindo-se, portanto, deste processo, o Ministro de Educação e Saúde (BOMENY, 2010, p. 278). Nos arquivos de Getúlio Vargas existia um projeto de decreto-lei (de 11 páginas), de agosto de 1938, juntamente com proposta de Regulamento Técnico-Disciplinar (com 41 páginas), sobre a Organização Nacional da Juventude, que nunca foi editado. Apesar de excluído das discussões do projeto, o Ministro de Educação e Saúde, Gustavo Capanema, envia ao Presidente da República as suas impressões sobre o projeto, oportunidade em que faz ressalvas como essa: "a juventude de oito a 18 anos passa a constituir uma tropa rigorosamente enquadrada, com um aparelhamento, uma disciplina, um método, uma atitude em tudo militares. Não acredito que tal organização seja aplaudida em nosso meio.” Apesar de tal crítica, o Ministro defendia que a organização deveria ser incluída entre os serviços do Ministério da Educação e Saúde (BOMENY, 2010, p. 287-290).

${ }^{29}$ O estudo de Helena Bomeny é exatamente sobre a relação entre Francisco Campos e a Organização Nacional da Juventude, ao analisar as suas referências no Livro "o Estado Novo". (BOMENY, 2010, p. 273 e ss). 
Para que se tenha melhor dimensão de tal projeto, note-se que o artigo primeiro do projeto de decreto-lei trazia como finalidade da Organização Nacional da Juventude: “[...] assistir e educar a mocidade, organizar para ela períodos de trabalho anual nos campos e oficinas, promover-lhe a disciplina moral e o adestramento físico, de maneira a prepara-la ao cumprimento dos seus deveres para com a economia e a defesa da Nação” (BOMENY, 2010, p. 279-280). Eis o pretendido retorno do então Ministro da Justiça ao contexto da educação.

A Criação da ONJ, no entanto, não obteve êxito diante da divergência de interesses dos Ministérios da Justiça e da Educação. Contudo, isso não evitou o surgimento de uma nova proposta para reforçar a autoridade do Exército e incluir na formulação da proposta o Ministério da Educação e Saúde. Ocorreu a criação da Juventude Brasileira ${ }^{30}$ (JB) (BOMENY, 2010, p. 295).

Por trás de tal divergência entre formatos (ONJ ou JB) da ideia de uma juventude nacional, Helena Bomeny explica que existia a figura de Francisco Campos e a sua relação com a “Ação Integralista Brasileira” - AIB, de Plínio Salgado. A AIB era essencial para o Golpe de 1937, em decorrência de sua ideologia anticomunista ${ }^{31}$. A ideia da "Organização Nacional da Juventude" foi utilizada, antes do golpe, como uma maneira de trazer como aliada a AIB - a quem fora prometida a Pasta da Educação. No entanto, passado o Golpe, essa expectativa foi frustrada, segundo Plínio Salgado (BOMENY, 2010, p. 302). No entanto, mais do que isso, a transformação da ONJ em um movimento cívico "teve um significado político que não deve ser desprezado: o de freio à pretensão de liderança de Francisco Campos” (BOMENY, 2010, p. 307).

30 Tratava-se do decreto-lei $n^{\circ}$ 2.072, de 02.03.1940. As finalidades a que se propunha a Juventude Brasileira, em proveito da infância e da juventude, são essencialmente: a) a educação moral, cívica e física; b) a educação pré-militar; c) a educação doméstica. Merece menção que no texto está especificado que a educação pré-militar será só para os homens e a doméstica só para as mulheres. Não bastasse isso, havia ainda os objetivos: para o homem, incentivar o amor ao dever militar; para a mulher, das os conhecimentos necessários ao desempenho de sua missão de mães e donas de casa (BOMENY, 2010, p. 297).

31 Para um aprofundamento sobre a ideologia anticomunista no período Vargas, ver: MARQUES, 2011. ${ }^{39}$ Nesse sentido, Francisco Campos esclarece quais são as propostas sobre a educação previstas na constituição de 1937: “A Constituição prescreve a obrigatoriedade da educação física, do ensino cívico e de trabalhos manuais, e atribui ao Estado, como seu primeiro dever em matéria educativa, o ensino provocacional e profissional, destina às classes menos favorecidas, cabendo-lhe ainda promover a disciplina moral e o adestramento da juventude, de maneira a prepara-la ao cumprimento de suas obrigações com a economia e a Defesa da Nação" (CAMPOS, 2001, p. 67, grifo nosso). 
Note-se que Francisco Campos, em suas empreitadas na seara da educação, sempre defendeu uma noção de centralização e controle ${ }^{39}$. No entanto, a realidade brasileira, e em especial a das universidades, precisa ser necessariamente plural. Essa contradição aparece na relação entre gênero, democracia e Francisco Campos, nas palavras de Helena Bomeny: "Mas as conquistas de gênero fazem parte justamente do modelo de democracia frágil, insustentável, imprópria e inadequada ao livre curso da sociedade de massas... Suponho que tais conquistas conformariam um cardápio indigesto ao intelectual erudito e jurista mineiro Francisco Campos” (BOMENY, 2010, p. 311). Reconstruir esses pontos da atuação de Francisco Campos demonstram os possíveis significados das remissões nos julgados do STF.

\section{CONCLUSÃO}

Desconstruir uma identificação entre a autonomia prevista na constituição de 1988 e aquela da reforma universitária de 1931 parece importante para desvendar algumas das edificações de sentido sobre o princípio. Por que a reforma de 1931, tão centralizada e controladora, permanece nos discursos do Supremo Tribunal Federal?

Uma possível pista pode ser encontrada nas palavras de Cristiano Paixão, afinal [...] tradições, práticas políticas e atitudes mentais são difíceis de mudar. Ainda que de forma latente, elas permanecem norteando o imaginário da sociedade, quer por manifestações de puro irracionalismo, quer pela lembrança de um passado que se revela repentinamente idílico, confortante e feliz. No caso brasileiro, essas tradições vêm marcadas pela herança autoritária. (PAIXÃO, 2006, p.

4).

Pode-se verificar uma manutenção do discurso autoritário que permanece com ecos até os dias de hoje. Se pensada essa disputa no contexto do sujeito constitucional, Rosenfeld (2003, p. 21) recorda que a "identidade constitucional compete com outras identidades relevantes, opondo-se a elas”. E essa disputa pode ocorrer entre períodos constitucionais bastantes distintos (autoritário, antes de 1931, e democrático, pós 1988).

No entanto, não se nega que ocorra certa incorporação de identidades anteriores (o que seria impossível), mas essa relação não pode eliminar o novo sentido da nova identidade constitucional. Uma interessante solução seria : a “[...] identidade constitucional pode se distanciar o suficiente de outras identidades relevantes contra as quais ela precisa forjar sua própria imagem, enquanto, ao mesmo tempo, incorpora elementos suficientes dessas identidades para continuar viável no interior de seu próprio ambiente sociopolítico” (ROSENFELD, 2003, p. 23). 
Talvez um bom passo - que aparece entre as pretensões dessa pesquisa - seja demonstrar um pouco dos significados da reforma universitária de 1931. Tomando-se certa ciência de seu caráter centralizador, espera-se chamar atenção para as conexões - seja em decisões judiciais ou em trabalhos acadêmicos - de uma construção de sentidos que equipara aquela autonomia à de 1988.

\section{REFERÊNCIAS}

BRASIL. Decreto n ${ }^{\circ}$ 19.547, de 10 de dezembro de 1930. Cassa a autonomia didática à Universidade de Minas Gerais. Diário Oficial [da] República Federativa do Brasil. Disponível em: http://www.planalto.gov.br/ccivil_03/decreto/1930-1949/D19547.htm Acesso em 20 de junho 2013.

. Decreto nº 19.851, de 11 de abril de 1931. 1931a. Dispõe sobre a organização do ensino superior no Brasil e adota o regime universitário. Diário Oficial [da]

República Federativa do Brasil. Disponível em: http://www. planalto.gov.br/ccivil_03/decreto/1930-1949/D19851.htm Acesso em 20 de junho 2013.

. Decreto $\mathrm{n}^{0}$ 19.852, de 11 de abril de 1931. 1931b. Dispõe sobre a organização da Universidade do Rio de Janeiro. Diário Oficial [da] República Federativa do Brasil. Disponível em: http://www.planalto.gov.br/ccivil 03/ decreto/1930-1949/D19852.htm. Acesso em 20 de junho de 2013.

. SUPREMO TRIBUNAL FEDERAL. Ação direta de inconstitucionalidade ${ }^{0}$ 519/RJ. Rel. Min. Paulo Brossard. Pleno. Brasília, J. em 25.10.1989. Diário de Justiça [da] República Federativa do Brasil, de 17.09.1993.

- SUPREMO TRIBUNAL FEDERAL. Medida Cautelar na ação direta de inconstitucionalidade $\mathrm{n}^{\circ}$ 1599-1/DF. Rel. Min. Celso de Mello. Pleno. Brasília, J. em 16.10.1996. Diário de Justiça [da] República Federativa do Brasil, de 06.06.2003.

BOMENY, Helena. Newton Sucupira e os rumos da educação superior. Brasília: Paralelo 15, Coordenação de Aperfeiçoamento de Pessoal de Nível Superior, 2001.

. Antiliberalismo como convicção: teoria e ação política em Francisco Campos. In: LIMONCIC, Flávio; MARTINHO, Francisco Carlos Palomares (Org.). Os intelectuais do antiliberalismo: alternativas à modernidade capitalista. Rio de Janeiro: Civilização Brasileira, 2010, p. 263-315.

CAMPOS, Francisco. Educação e Cultura. Rio de Janeiro: Livraria José Olympio Editora, 1940. 

Deputados, 1979.

A política e o nosso tempo, Diretrizes do Estado nacional e Problemas do Brasil e soluções do regime. In: . O Estado Nacional: sua estrutura; seu conteúdo ideológico. Brasília: Senado Federal, 2001.

CALMON, João. A educação e o milagre brasileiro. Rio de Janeiro: Livraria José Olympio Editora, 1974.

CONDORCET, Jean-Antoine-Nicolas de Caritat, Marquis de. Cinco memórias sobre a instrução pública. Trad. Maria das Graças de Souza. São Paulo: UNESP, 2008. CUNHA, Luiz Antônio. A Universidade Temporã. Rio de Janeiro: Livraria Francisco Alves Editora, 1981. . O público e o privado na educação superior brasileira: fronteira em movimento? In: TRINDADE, Hélgio. Universidade em ruínas: na república dos professores. Petrópolis: Vozes / Rio Grande do Sul: CIPEDES, 1999, p. 125-148.

. Por uma lei orgânica do ensino superior. In: APPEL, Emmanuel (org.) $A$ universidade na encruzilhada - Seminário Universidade: por que e como reformar? Brasília: UNESCO Brasil, Ministério da Educação, 2003, p. 147-154.

. A universidade crítica: o ensino superior na república populista. 3. ed. São Paulo:

UNESP, 2007.

FÁVERO, Maria de Lourdes de A. Autonomia universitária: necessidades e desafios. Cadernos CEDES 22 - Educação superior: autonomia, pesquisa, extensão, ensino e qualidade. São Paulo: Cortez Editora, 1988.

FÁVERO, Maria de Lourdes de A. A universidade em questão: como resgatar suas relações fundamentais? In: . (org.) A universidade em questão. São Paulo: Cortez Autores Associados, 1989.

FERRAZ, Ana Cunha. O regime especial das autarquias educacionais. Revista da Procuradoria-Geral do Estado de São Paulo, São Paulo, vol. 17, 1980, p. 201-222. GIROUX, Henry. Ensino Superior para quê? Trad. Elisabeth Seraphim Prosser. Educar, Curitiba, n. 37, 2010.

GUSTIN, Miracy Barbosa; DIAS, Maria Tereza Fonseca. (Re)pensando a pesquisa jurídica: teoria e prática. 2. ed. Belo Horizonte: Del Rey, 2006.

LINHARES, Mônica Mansur. Autonomia universitária no direito educacional brasileiro. São Paulo: Segmento, 2005. 
MARQUES, Raphael Peixoto de Paula. Repressão política e usos da Constituição no Governo Vargas (1935-1937): a segurança nacional e o combate ao comunismo. Dissertação de Mestrado. Faculdade de Direito da Uub. Brasília, 2011.

MARTINS, Geraldo Moisés. Universidade Federativa, Autônoma e Comunitária.

Brasília: Athalaia Editora, 2008.

MAYORGA, Claudia; COSTA, Fabíola Cristina Santos; CARDOSO, Tatiana Lúcia. Universidade pública no Brasil: entre privilégios e direitos. In: MAYORGA, Claudia. Universidade cindida, universidade em conexão: ensaios sobre a democratização da universidade. Belo Horizonte: Editora UFMG, 2010, p. 19-45.

MEDEIROS, Jarbas. Introdução ao estudo do pensamento político autoritário brasileiro 1914/1945. Revista de Ciência Política, Rio de Janeiro, v. 17, n. 1, 1974.

MORIN, Edgar. Os sete saberes para a educação do futuro. Trad. Ana Paula Viveiros. Lisboa: Instituto Piaget, 2002.

MOTA, Carlos Guilherme. Para uma visão de conjunto: a história do Brasil pós-1930 e seus juristas. In: MOTA, Carlos Guilherme; SALINAS, Natasha Schimitt Caccia (coord). Os juristas na formação do estado-nação brasileiro: (de 1930 aos dias atuais). São Paulo: Saraiva, 2010, p. $25-141$.

PAIXÃO, Cristiano. Autonomia Universitária e civilização: dimensões do debate atual. In: . (org.) Redefinindo a relação entre o professor e a universidade: emprego público nas Instituições Federais de Ensino? Coleção “O que se pensa na colina”.

Brasília: Faculdade de Direito, CESPE, 2002, v. 1, p. 13-20.

. Modernidade, Tempo e Direito. Belo Horizonte: Del Rey, 2002.

- Arqueologia de uma distinção - o público e o privado na experiência histórica do direito. In: PEREIRA, Claudia Fernanda Oliveira (org.). O novo direito administrativo brasileiro. Belo Horizonte: Fórum, 2003.

PROST, Antoine. Doze lições sobre a história. Trad. Guilherme João de Freitas Teixeira. Belo Horizonte: Autêntica, 2008.

RANIERI, Nina. Autonomia Universitária: as Universidades Públicas e a Constituição Federal de 1988. São Paulo: Editora da Universidade de São Paulo, 1994.

Aspectos Jurídicos da Autonomia Universitária no Brasil. In: STEINER, João E.; MALNIC, Gerhard (org.). Ensino Superior: conceito \& dinâmica. São Paulo: EDUSP, 2005a. Disponível em: http://www.iea.usp.br/observatorios/ensinosuperior. Acesso em: 25.01.2010. 
Aspectos Jurídicos da Autonomia Universitária no Brasil. Revista CEJ,

Brasília, v. 9, n. 31, Brasília, 2005.

RIBEIRO, Darcy. Aos trancos e barrancos: como o Brasil deu no que deu. Rio de Janeiro: Guanabara Dois, 1985.

A Universidade Necessária. 5. ed. São Paulo: Paz e Terra, 1991.

RICOEUR, Paul. A memória, a história, o esquecimento. Campinas: Editora da UNICAMP, 2007.

RIOUX, Jean-Pierre. Pode-se fazer uma história do presente? In: CHAVEAU, Tetard A.

(org.) Questões para a história do presente. Trad. Ilka Stern Cohen. Bauru: EDUSC, 1999.

ROMANELLI, Otaíza de Oliveira. História da Educação no Brasil: (1930/1973). 36.

ed. Petrópolis: Vozes, 2010.

ROMANO, Roberto. Gestão universitária, autonomia, autoritarismo. Revista da USP. São Paulo, n. 78, 2008.

ROSENFELD, Michel. A Identidade do Sujeito Constitucional. Trad. Menelick de Carvalho Netto. Belo Horizonte: Mandamentos, 2003.

SALMERON, Roberto Aureliano. Discurso proferido ao receber o título de doutor honoris causa pela Universidade de Brasília. Passagens de Paris 2, 2005.

A universidade interrompida: Brasília 1964-1965. 2. ed. Brasília: Editora Universidade de Brasília, 2007.

SAMPAIO, Anita Lapa Borges. Autonomia Universitária: um modelo de interpretação do artigo 207 da Constituição Federal. Brasília: Editora da Universidade de Brasília, 1998.

SAMPAIO, Helena Maria Sant'ana. Expansão do Ensino Superior. In: MORHY, Lauro (org.).

Universidade em questão. Brasília: Editora Universidade de Brasília, 2003, p. 143-161.

SCHWARTZMAN, Simon. In: associação brasileira de mantenedoras de ensino superior; fundação nacional de desenvolvimento do ensino superior particular (org.). Políticas Públicas de Educação Superior. Brasília, 2002.

SEELAENDER, Airton Cerqueira-Leite; CASTRO, Alexander Rodrigues de. Um jurisconsulto adaptável - Francisco Campos (1891-1968). In: MOTA, Carlos Guilherme;

SALINAS, Natasha Schimitt Caccia (coord.). Os juristas na formação do estado-nação brasileiro: (de 1930 aos dias atuais). São Paulo: Saraiva, 2010.

SORJ, Bernardo. A democracia inesperada: cidadania, direitos humanos e desigualdade social. Rio de Janeiro: Jorge Zahar, 2004. 
TEIXEIRA, Anísio. Administração Pública: administração e desenvolvimento. Rio de Janeiro:

Officina Graphica do Departamento de Educação, 1934.

. Educação no Brasil. São Paulo: Companhia Editorial do Livro, 1976.

. Ensino Superior no Brasil: análise e interpretação de sua evolução até 1969. Rio de Janeiro: Fundação Getúlio Vargas, 1989.

. Aspectos americanos de educação: anotações de viagens aos Estados Unidos em 1927. Rio de Janeiro: Editora UFRJ, 2006.

TRINDADE, Hélgio. Apresentação. In: . Universidade em ruínas: na república dos professores. Petrópolis: Vozes; Rio Grande do Sul: CIPEDES, 1999, p. 7-8.

. Universidade, Ciência e Estado. In: . Universidade em ruínas: na república dos professores. Petrópolis: Vozes; Rio Grande do Sul: CIPEDES, 1999, p. 9-23.

. A Urgência da Autonomia Universitária. In: MORHY, Lauro (org.).

Universidade em questão. Brasília: Editora Universidade de Brasília, 2003, p. 259-273. UNIVERSIDADE FEDERAL DE MINAS GERAIS. História da UFMG. Disponível em: http://www.ufmg.br/conheca/hi_index.shtml. 2011a. Acesso em 19.11.2013. 